\title{
A STUDY OF IMPACT OF E-COMMUNICATION ON WRITTEN ENGLISH PRACTICED BY UNDERGRADUATE STUDENTS
}

\author{
Dr. Jagdish Joshi \\ Dr. Rajani Suthar \\ Ms Jill Joshi
}

\begin{abstract}
In present time, the phenomenon of 'globalization' has been largely possible due to increased popularity of e-communication and digitization of information. Additionally, the ready availability of computers and internet has contributed in 'linking' the world together into a single whole. It has transformed human life and environment; and has fulfilled the innate human desire for speed. And by using various e-tools, such as emails, social networking sites, mobiles, blogs and others, fast paced communication has been made possible. Consequently, the modern scenario of communication has changed forever. It has helped in improving the standard of living and has enabled faster, clearer and more accurate outcome to the designated tasks. The young generation is increasing moving towards using the e-mode for communication. The youth of India are becoming more and more techno friendly. They use e-tools like smart phones, laptops, tablets etc. excessively for interaction and communication. Moreover, use by doing research on the above mentioned topic the researchers wish to get an insight into an extremely current topic, namely, the connection between use of e-communication and the change in the method of communication and language, specifically written English, due to its wide-spread use. In order to make the research more pointed, the researcher has decided to study a specific target group of youngsters, namely, undergraduate students and evaluate their writing pattern. By carrying out research in the proposed topic, the researchers attempt to analyze the impact of e-mode on the English language.Moreover, they wish to specifically investigate the kind of impact e-communication has had on written English of these students: Whether it actually has had an impact or not; and to what extent it has transformed the English used by them or is it the other way around?
\end{abstract}

Keywords: E-communication, English, technology, digital, globalization, language etc. 


\section{Introduction}

Oxford Dictionary and Thesaurus III defines 'communication' as, "science and practice of transmitting information (140)."In other words, it refers to the give and take of information between individuals through a common medium. And ' $e$ ' is an abbreviation of 'electronic' which has been defined as Concise Oxford Dictionary as

adj.

1 having components such as microchips and transistors that control and direct electric currents.

2 (of music) produced by electronic instruments.

3 of or relating to electrons or electronics.

4 carried out using a computer, especially over a network: electronic shopping (COD).

The term 'e-communication' has become very popular, in present time, and in the simplest sense it means communication that 'takes place' or 'is facilitated' by electronic medium. The various available e-tools for communication may be broadly divided into two types, namely, tools for composing message or data to be communicated and tools for transferring the message or data. In present times, both the types of tools have sophisticated features and numerous options. The type of data or message to be composed and communicated determines the tools to be used in the communication process.

Electronic communication technology has been revolutionized the composing process and participation in writing activities. Communication technology is composed of many forms of electronic communication. Those associated with the internet, now accessible through both computers and mobile phones (Omar and Miah).

\section{English Usage in E-communication}


With the changing times, English has undeniably emerged as a truly international language, spoken in many countries both as a native and as a second or foreign language. The 'globalization' phenomenon in the present time and the 'colonization' in the past have played a vital role in the increase in popularity of English. The technological boom has also contributed immensely to the increase in usage of English. In addition to this, technology, in present time, has become cost-effective and easily accessible to all. The wide spread use to technological gadgets for communication has also added to its eminence. English, because of its popularity across the globe, was able to conveniently carve its niche as world language. Undoubtedly, it rose in status and went on to become the undisputed winner of the title 'world language'. The language has been used world-wide as apt for carrying out legal, business, professional transactions as it is less vague as compared to other languages. It is accurate and can be learnt and understood easily due to its simple grammatical and limited inflexions.

\section{Research Methodology Employed in Paper}

The researchers wish to discuss the impact of e-communication on English from the point of view of structure, grammar, punctuation, code language, symbol usage, abbreviation, transliteration. The researcher uses to adopt the survey method and to present a format of the questionnaires, collect data and analyze the data collected. In addition to this, the researcher wishes to depict transformation of English, namely, due to the extensive use of electronic medium for communication used by target group, namely, under-graduate students.

\section{Questionnaire and Data Collection}

\section{QUESTIONNAIRE}

Topic: Research on effects of E-communication on written English of UG Students

Name: Class \&Div:

Roll No.

1. Do you have a smart phone: $Y$

No

2. Which is your preferred medium of communication: Cellphone Computer $\square$ Laptop Tablet

3. Do you communicate by e-mode i.e.Email, Facebook, Twitter, Whatsapp/Hike/Line, Blogs etc 
Yes $\square$

If yes, please tick the different modes that you use:

Email

Twitter

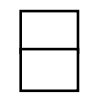

Facebook

Whatsapp/Hike/ Line
Linkedin

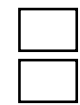

4. Do you use abbreviations in written text (for e.g. 'v 'instead of ' we' or 'cu' instead of see you ):

Yes

1.

2.

the most instead of

3. instead of instead of

4. instead of

5. instead of

6. Do you use skip articles('a', 'an' and 'the')
Always
Sometir $\square$
Never $\square$

7. Do you use translated text or infusion of foreign words of vernacular languages like Hindi etc.
Yes
No

8. If yes, tick option applicable:
Always
Most of the tim $\square$
Sometime $\square$

9. Do you skip using punctuations( such as ,.?!) in writing

$$
\text { Yes } \square \text { No } \square
$$

10. If yes, specify frequency:
Always
Most of the time
Sometime $\square$

11. Do you indulge in overuse of punctuations

$$
\text { Yes }
$$

No

12. If yes, specify frequency:
Always
Most of the tim
Sometime

13. Do you use emoticons (or smileys as it is commonly called) in your text
Yes
No $\square$

14. If yes, specify frequency:
Always
Most of the tim
Sometime

15. How often do you write incomplete sentences or only words instead of sentences
Always
Most of the tir $\square$
Som $\square$ hes
$\square$ ver

16. Do you use code language or numeric language instead of words (for e.g. 4 instead of _ur')Always $\square$ st of the time $\square$ Bometimes

\section{Never}

17. If yes, please write the most frequently used code language:

1. instead of

2. instead of

3. instead of 
Your Signature:

A survey was conducted by asking 50 UG students of Shree Narayana College of Commerce to fill the above mentioned questionnaire and data was collected and analyzed thereafter.

\section{Popularity of E-tools for Communication among Youngsters as Represented by Under-graduate Students}

Over the years, English has emerged as a prolific, popular and powerful language. It has become one of the most used languages of the world and has been tagged by many as the most preferred language among all. English occupies the remarkable place of an 'International' language. It is used by the maximum number of people across the globe. This rise in popularity of the English language has been for a variety of reasons. There are a number of factors that have contributed to its ascent.

\section{Impact of E-communnication on Written English Language of Under- Graduate Students as Noticed in Data Analysis}

The overall impact from the samples can be elucidated as follows:

\subsection{Smart Phone Usage}

Welcome to the new age mobile phones, aptly called smart phones. Over and above the tuxedo clad businessmen who strut it around, youngsters who want to be connected all the time and women who appreciate the cool applications...3G spectrum is to change the face of telecommunications in the country as the downloading time will be lesser for all the applications. That sort of growth naturally attracts entrepreneurs who want to capitalize on the Internet enabled mobile devices (Chawla 6).

Thus, smart phones are no longer used by privileged few but all can afford smartphones including youngsters-under graduate students. The study reveals that $84 \%$ of UG students possess cellphones and use it on daily basis which is a substantial amount. 


\section{Do you have a smart phone?}

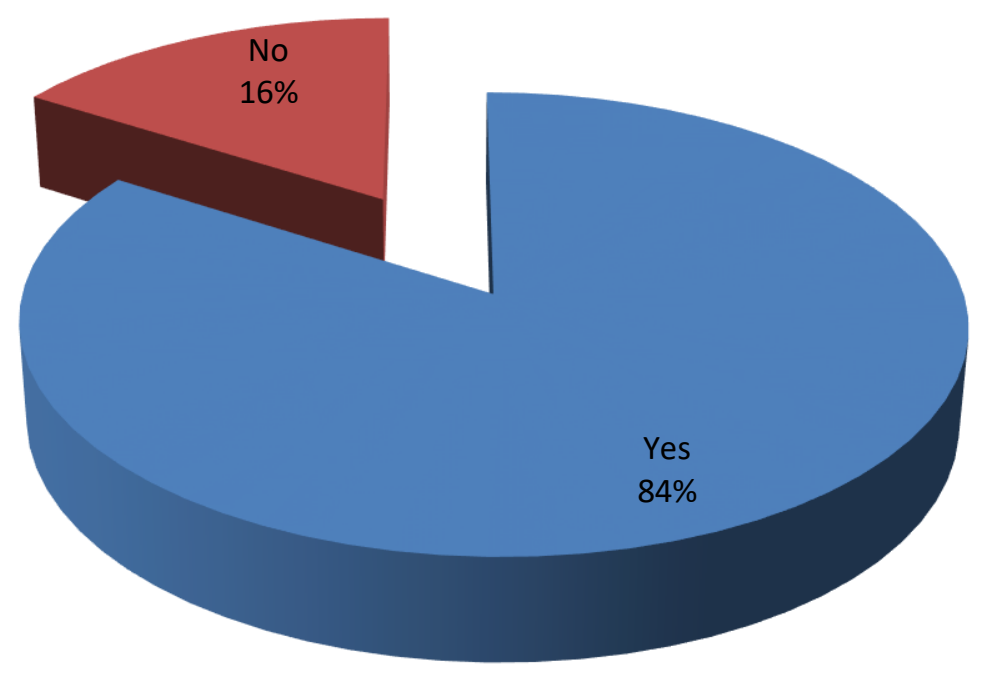

\subsection{Preferred medium of communication}

One of the significant features of e-communication is 'mobile technology' which stands for exactly what its name precisely implies- technology that is portable. Mobile IT devices are of different types: portable computers like laptops, palmtops, PDA, cell-phones (with integrated technology), GPS devices, wireless credit/debit card systems. When the students were asked to chose their preferred gadget, a startling $68 \%$ chose cellphone as their favourite. The tool used affects the style of writing and hence this detection reveals that the message is typed using a touch screen device and not a keyboard when cellphone is used for texting. Hence, it can be considered as a contributing factor to the discrepancies seen in texting and writing. 


\section{Which is your preferred medium of communication?}

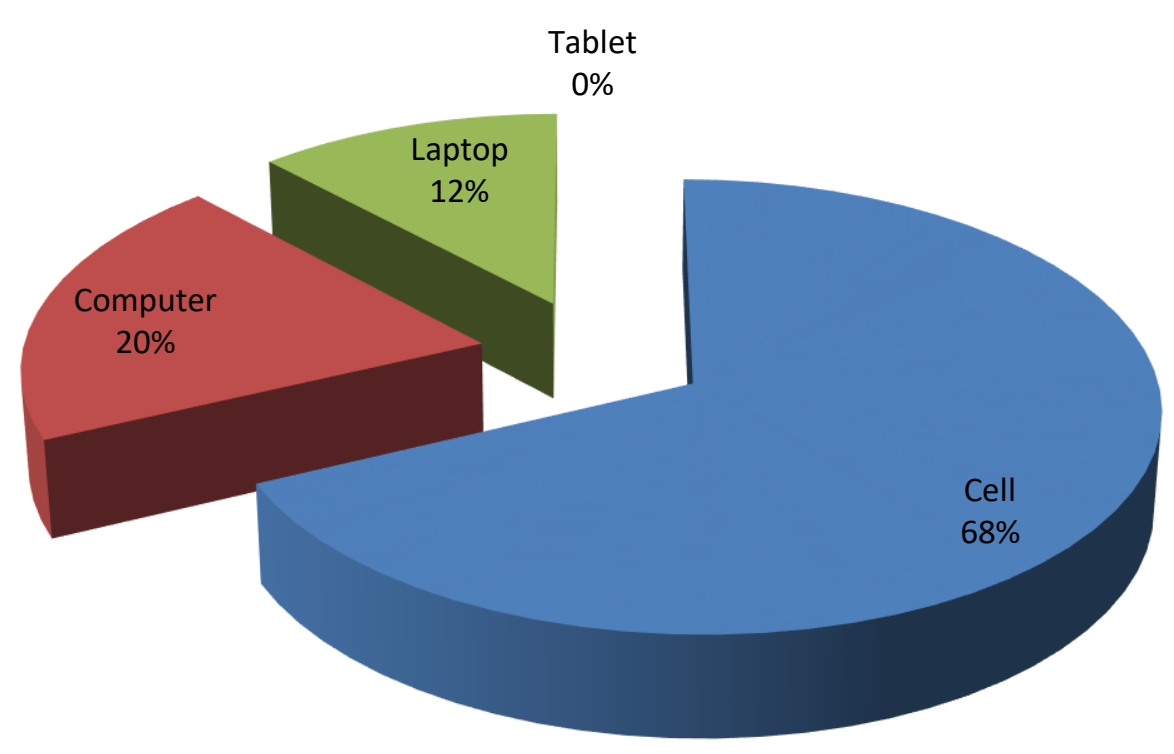

\subsection{Favourite Data Transmitting E-tool}

Just as composition of data to be communicated is important, in the same way, the channel or the medium used for sending the data also bears significance. Depending on the type of data to be transmitted, the purpose and the person/s to whom the data is being transmitted, the tools required for transferring it can be determined. In the present age, with the latest technological advancements and the IT boon, there are plenty of options available to suit an individual's specific needs. The students have selected Whatsapp/Hike/Line as their preferred mode of data transfer with $56 \%$; whereas Blog has received $0 \%$ preference. This finding indicates that students prefer 'brevity' and speed in their communication. 


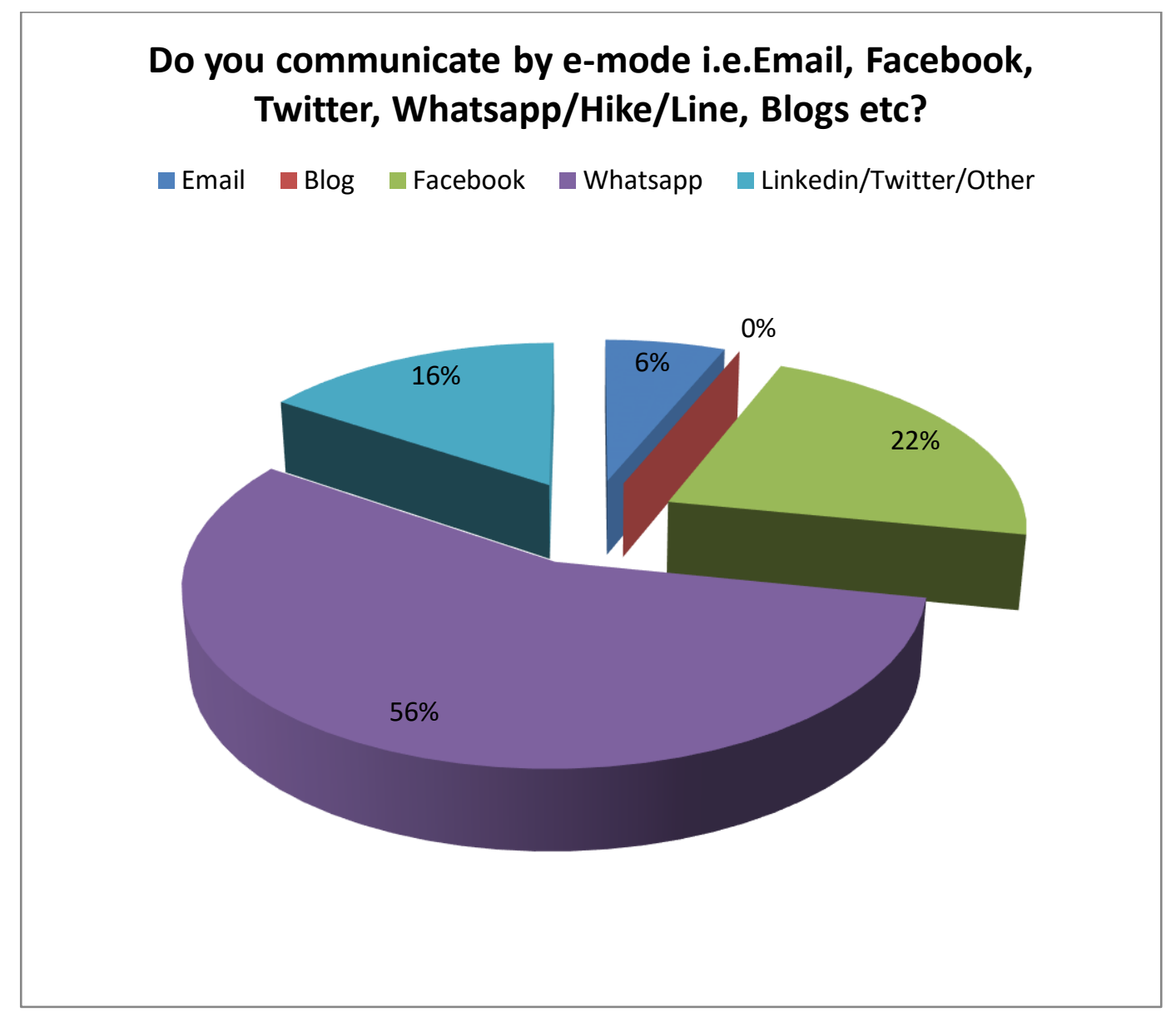

\subsection{Use of abbreviations}

The constant need for speed in communication through English via the e-mode has resulted in usage of simpler version of words. This phenomenon has increased the use of abbreviations and acronyms in English. All 50 students have put a tick on 'Yes'. Which means that all use abbreviations.

\subsection{Article Usage}

Ecommunication English is written, undoubtedly, in speedier manner than any other form of written communication. This aspect of speed was not present in the earlier forms of written communication and has made a significant impact on the language used for communication; the element of speed, hastiness and immediacy is also evident in the language in it. In a desire to communicate or to reply instantly the users have begun to omit articles. All students have skipped writing articles. 8\% students always skip them whereas $92 \%$ skip them sometime-which is a sizeable amount. 


\section{Do you use skip articles?}

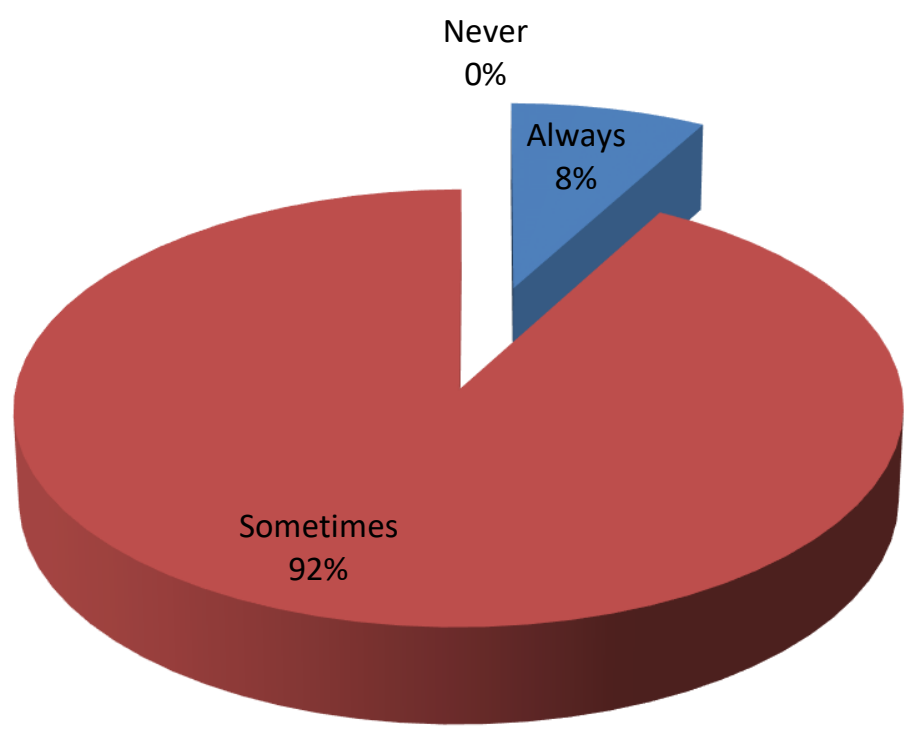

\subsection{Transliteration or Infusion of Vernacular Language}

Words or salutations from the mother tongue are transliterated and in English and blended with English sentences. One of the most noticeable trends which emerge in usage of English via e-mode is that of transliteration. With multilingualism and bilingualism become a common occurrence, different languages can no longer exist in isolation and humans can no longer communicate in single language alone. This trend can be noticed absolutely clearly in the following charts: 

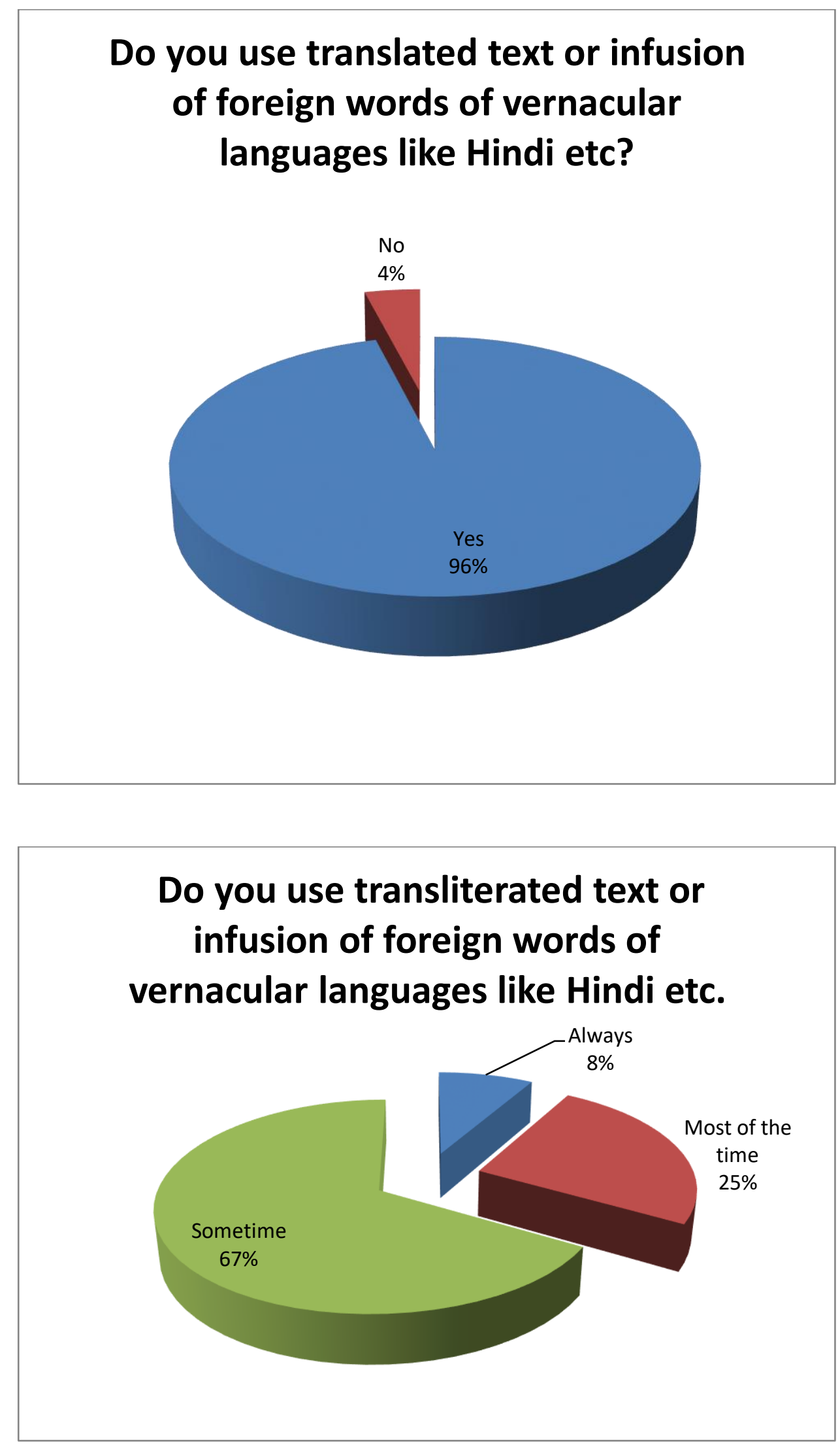


\subsection{Punctuation usage}

Hokanson makes a very valuable point on use of punctuation when he says, "punctuation tends to be minimalist in most situations, and completely absent in some emails and chat exchanges." In some e-text versions, use of punctuation marks is minimal. Whereas some instances of inappropriate use of punctuation marks can also be detected, such as use of several exclamatory marks: '!!!!' to express excitement or use of full stops: '......' to demarcate a break or end. There are number of findings about transformation in punctuation usage by UG students. They have been revealed in the following graphs:-

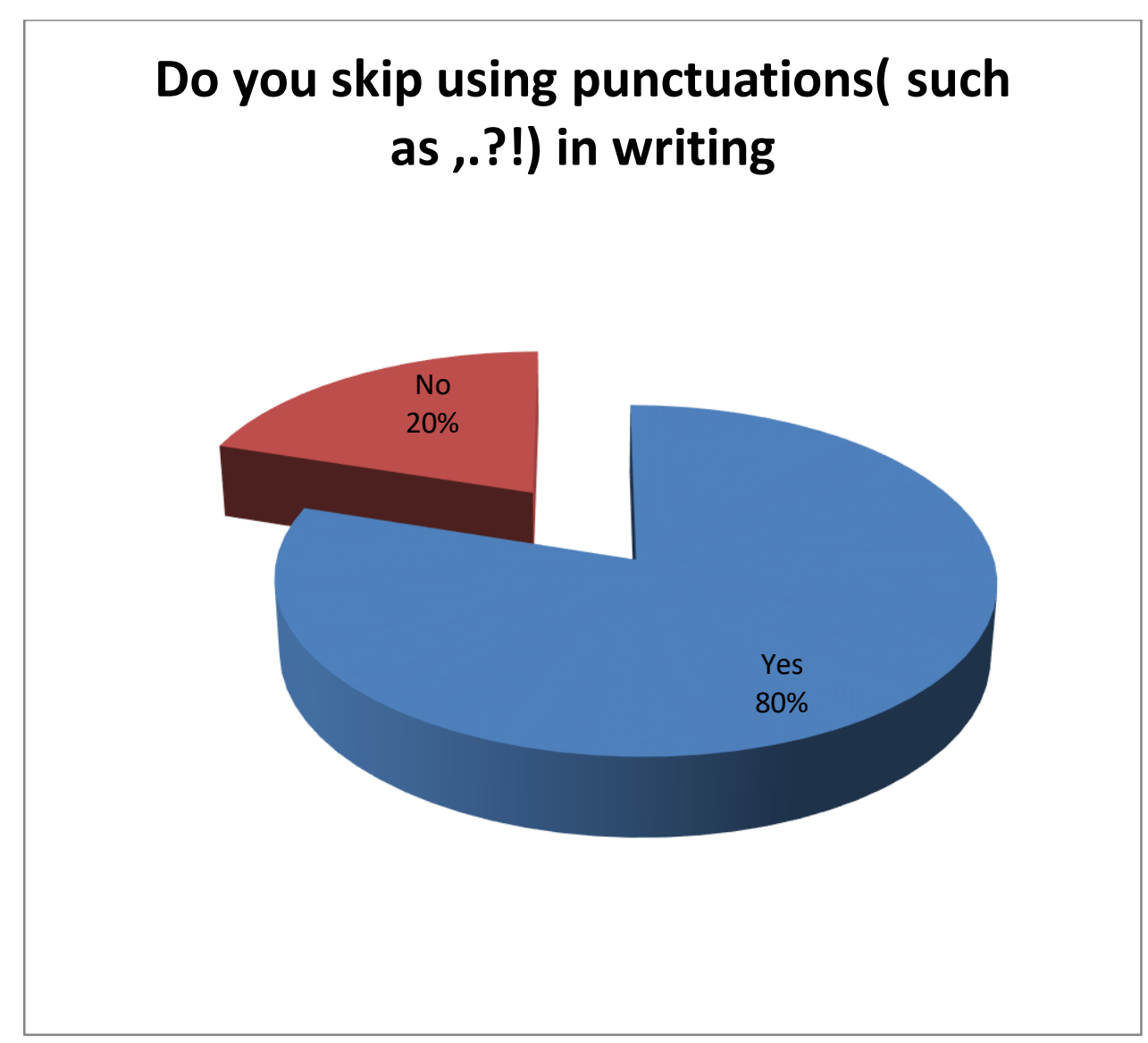



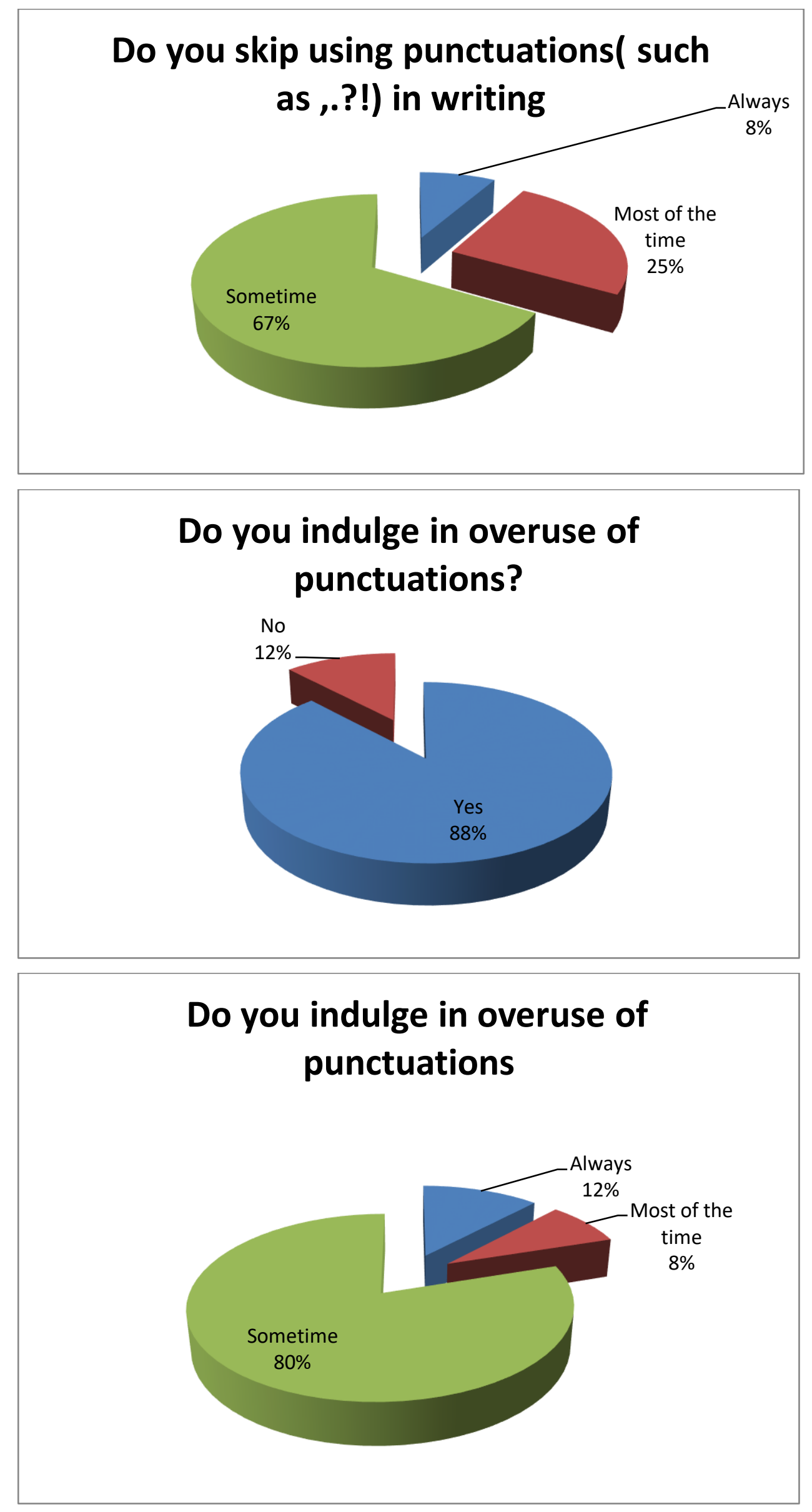


\section{8. Use of emoticons}

In text messages, 'emoticons'(icons reflecting emotions) are commonly used to show mood in ecommunication messages. Emoticons have become a popular way to express one's feelings and frame of mind which was not used so extensively in communicating through traditional modes. All 50 students have put a tick on Yes. It means that all of them use emoticons.

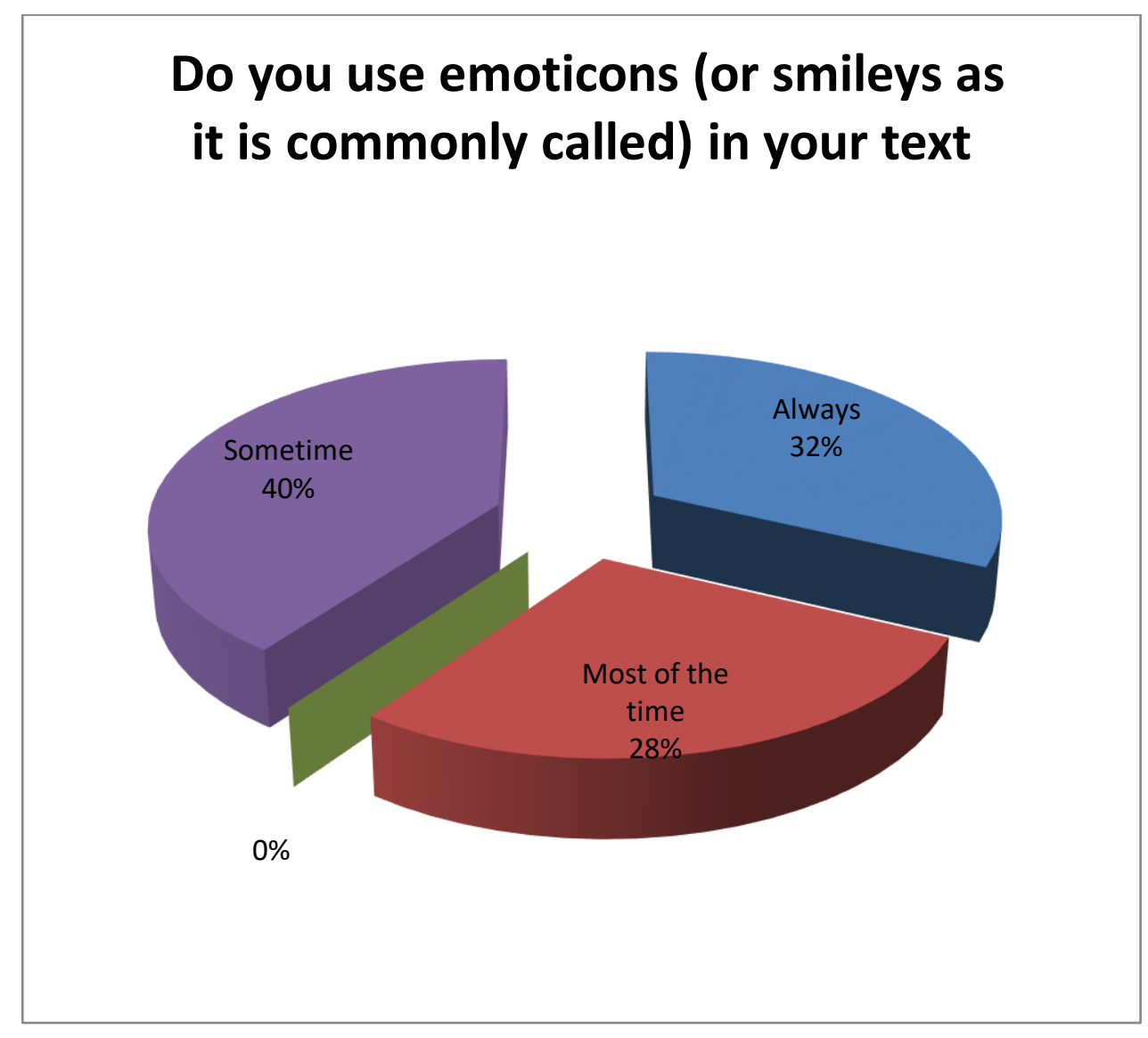

\subsection{Fragmentation}

Grammar is the epicenter of any language and English is no exception. If it loosensup, there are chances of fragmentation or distortion. It can also lead to sloppiness and incoherence. When one doesnot take the trouble to complete sentences- it can at times lead to miscommunication. But due to the dominance of element of speed in e-communication, fragmentation has become a common occurrence in written text UG students as can be seen in the chart below: 


\section{How often do you write incomplete sentences or only words instead of sentences}

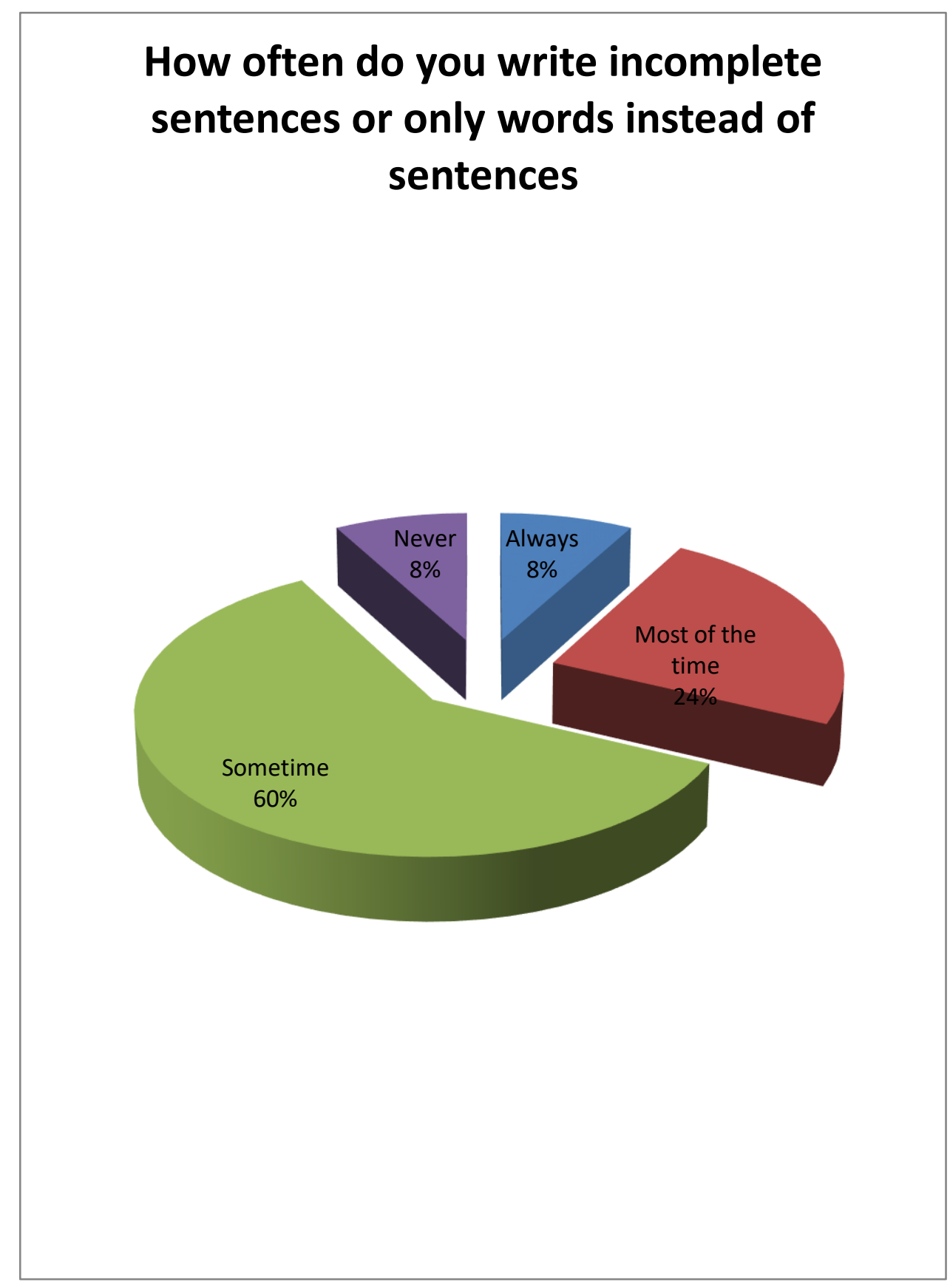

\subsection{Code language or Alpha-Numeric Language Instead of Words}

E-communcation is one such medium where humans have displayed their vein to test or modify their skills. Simplified forms of words have come into existence. The use of code-words such as 'Gr8' for great or 'b4' for before etc., appears to be increasing. This trend can be noticed when $48 \%$ of students say they use code language most of the time. 


\section{Do you use code language or numeric language instead of words (for e.g. 4 instead of 'four')?}

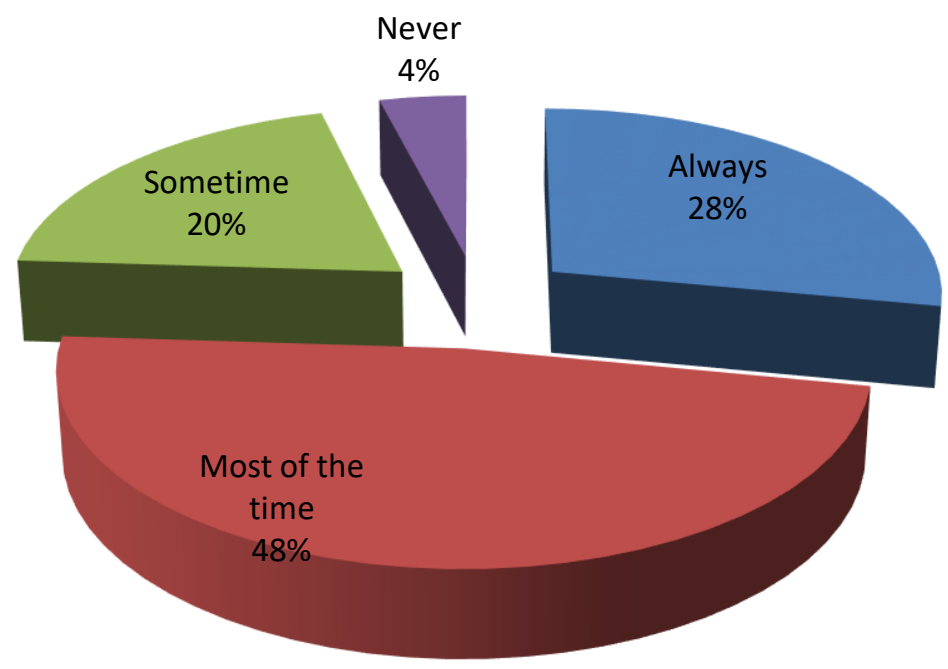

\section{Conclusion}

E-communication has, undoubtedly, been transformed and has to a large extent tried to adapt to the new advantages that technology has to offer, such as speed and simplicity. Written e-communication has also been privy to this trend. The samples reveal that these changes have seeped into the English language and transformed it's course forever. In addition to this, one noteworthy aspect is the tendency of playfulness or casualness in communication. Manypleasing options such as emoticons, code language and abbreviations are available to e-communication users. Lastly, flexibility in use of articles, punctuations etc. has transformed the course of written English practiced by UG students to a considerable extent as can be revealed in the survey. 


\title{
Works Cited
}

"communication." Concise Oxford Dictionary. 10th ed. UK: OUP, 2001. CD-ROM.

"communication." Oxford Dictionary and Theasurus III. Ed. Julia Elliott. New York:

OUP, 2001. Print.

Chawla, Khusboo. 'Tech your Mobile' Ahmedabad Times 13 June 2010: 6. Print.

Hokanson, Brad. The Impact of Internet on Language. 15 Dec 2013. Web.

Omar, Adnan and Muhammed Miah. International Journal of Advanced Trends in

Computer Science and Engineering. 'Impact of Technology on Teens' Written

Language'. 28 April 2012. Web.

< http://www.warse.ijatcse.current>

\author{
Dr. Jagdish Joshi \\ Professor and Director, \\ UGC Academic Staff College, \\ Gujarat University, Ahmedbad-380006. \\ \& \\ Dr. Rajani Suthar \\ Lecturer, ESL Dept., \\ University of Regina, \\ 3737 Wascana Parkway, \\ Regina, Saskatchewan, S4S 0A2 \\ \& \\ Ms Jill Joshi \\ C U Shah University
}

